\title{
Procedimento metodológico para análise da distribuição da chuva e extrato do balanço hídrico no semiárido: estudo de caso
}

\author{
Methodological procedure for analysis of rainfall distribution and water balance extract in the \\ semi-arid region: case study
}

\author{
M. G. Queiroz ${ }^{1 *}$; T. G. F. Silva²; G. N. Araújo Júnior²; A. M. R. F. Jardim²; M. J. \\ Silva $^{3}$; C. A. A. Souza ${ }^{2}$ \\ ${ }^{I}$ Departamento de Engenharia Agrícola, Universidade Federal de Viçosa, 36570-900, Viçosa-MG, Brasil \\ ${ }^{2}$ Unidade Acadêmica de Serra Talhada, Universidade Federal Rural de Pernambuco, 56909-535, Serra Talhada, \\ Brasil \\ ${ }^{3}$ Universidade Federal do Vale do São Francisco, 56304-917, Petrolina-PE, Brasil
}

\author{
*mg.gabi@hotmail.com
}

(Recebido em 27 de setembro de 2017; aceito em 27 de março de 2018)

\begin{abstract}
Para a região Semiárida, informações das condições hídricas são indispensáveis no estabelecimento de estratégias de manejo da produção agrícola. Assim, objetivou-se definir um procedimento metodológico para análise da variabilidade e anomalia da chuva e do extrato do balanço hídrico climatológico sequencial (BHCS), e suas tendências de mudanças ao longo do tempo. Para tal, foram usados dados de chuva do município de Carnaíba, referente à série de 1965 a 2006 e posteriormente submetidos à estatística descritiva, sendo proposta uma metodologia para detectar variabilidades e anomalias climáticas pelos desvios da precipitação pluviométrica. Em seguida, procedeu-se com análise de tendências dos dados anuais e mensais, sendo significativos desde que $\mathrm{p}<0,10$. Os resultados revelaram que a maior precipitação anual foi de $1921,5 \mathrm{~mm}$, e a menor de 49,6 mm. Houve tendência significativa de redução da precipitação apenas para o mês de junho $(\mathrm{p}<0,05)$ e para os valores anuais $(\mathrm{p}<0,10)$. Diagnosticou-se que $45 \%$ dos anos foram enquadrados na classe "Anos Normais", e que nos meses de agosto a outubro, o número de anomalias inferiores foi maior que 50\%. Em relação ao BHCS, apenas os componentes déficit hídrico e retirada de água do solo apresentaram tendências significativas. Verificou-se que, entre os anos de 1965 e 2006, os eventos de variabilidade e anomalia climática inferiores foram eventos mais frequentes, todavia, se devem a sua ocorrência nos meses mais secos e que houve oscilações anuais e mensais dos componentes do BHCS, indicando alta variabilidade do regime pluviométrico local.
\end{abstract}

Palavras-chave: variabilidade climática, precipitação, anomalia.

For the semiarid region, information of water conditions are indispensable to establish management strategies of agricultural production. Thus, aimed to define a methodological procedure for variability analysis and anomaly of rain and of the sequential climatic water balance (SCWB) extract, and your trends change over time. They were used rainfall data for the municipality of Carnaíba-PE, referring to the series from 1965 to 2006 and subsequently submitted to descriptive statistics, and proposed a methodology to detect variability and climate anomalies by deviations of rainfall. Then proceeded with trend analysis of annual and monthly data are significant since $\mathrm{p}<0.10$. The results showed that the highest annual rainfall was $1921.5 \mathrm{~mm}$ and less than $49.6 \mathrm{~mm}$. There was a significant trend of reducing precipitation only June $(\mathrm{p}<0.05)$ and the annual values $(\mathrm{p}<0.10)$. It was diagnosed $45 \%$ of the years were classified in the "Years Normal" class, and in the months of August, September and October, the number of lower anomalies was higher than $50 \%$. In relation to SCWB only the components water deficit and ground water withdrawal showed significant trends. It was found that between the years 1965 and 2006, the variability and climate anomaly of rain events, below normal climatological were more frequent events, however, it is due to its occurrence in the driest months and that there were annual and monthly fluctuations in SCWB components over the years analyzed, indicating high variability of local rain regime.

Keywords: climate variability, rainfall, anomaly. 


\section{INTRODUÇÃO}

A degradação de terras é um dos mais graves problemas ambientais regionais e globais, de modo que, todos os ecossistemas florestais apresentam consideráveis alterações de suas áreas originais, decorrentes principalmente de ações antrópicas [1-3]. As alterações do clima que vêm sendo observadas nas últimas décadas podem ser resultado da intensificação de atividades indústrias, sendo o aumento na concentração de alguns gases atmosféricos, apontados como os responsáveis pelo surgimento de eventos extremos: aumento da temperatura global, intensificação da variabilidade espacial e da magnitude dos valores de precipitação $[4,5]$.

Um dos setores extremamente susceptíveis às variações climáticas é a agropecuária, com destaque para a prática da agricultura de sequeiro, principal atividade desenvolvida na região Semiárida do Brasil, atrelada a pecuária extensiva praticada nesta região, onde os rebanhos, durante boa parte do ano, alimentam-se de espécies forrageiras da Caatinga [6]. No entanto, extensas áreas da Caatinga se encontram em estádios avançados de sucessão, com pouca ou nenhuma perspectiva de recuperação, devido a práticas de manejo pecuária extensivas.

Desta forma, o conhecimento prévio do comportamento da precipitação em escalas mensais e anuais, em termos de intensidade, duração e distribuição, bem como informações sobre o excesso e déficit hídrico local são dados valiosos, os quais condicionam o tipo de vegetação natural de determinada região, o tipo de exploração agrícola a ser desenvolvida, potencializa a agricultura não irrigada, influencia o ciclo hidrológico, e permite vislumbrar possíveis soluções para problemas hídricos $[5,7,8]$. Do mesmo modo, a avaliação de variabilidade climática e anomalias de chuva são interessantes, na medida em que a ocorrência destas condições exerce forte influência nas atividades humanas, ocasionando impactos na agricultura, recursos hídricos, saúde e meio ambiente [5].

Sendo o Brasil um país com grande extensão territorial, a realização de análises de séries climáticas, pode tornar-se difícil e/ou onerosa, visto que não são em todas as localizadas que existe a disponibilidade de sensores e/ou equipamentos para obtenção de dados meteorológicos. Em oposição, há uma demanda crescente no tocante a compreensão e análise do regime pluviométrico nos diversos ecossistemas brasileiros, numa respectiva de manutenção de um sistema mais sustentável possível.

Segundo Moura et al. (2007) [9] embora exista grande extensão territorial da região Semiárida, há pouca diversidade no clima das localidades inseridas nesta, sendo alguns fatores como o relevo e efeitos da oceanidade, os responsáveis pelos maiores índices pluviométricos observados em alguns locais. Souza e Azevedo (2012) [5] citam que é grande a necessidade de incluir resultados de áreas pouco estudadas, as quais podem ter acesso limitado, poucos registros e qualidade inferior de dados.

Diversas metodologias foram sugeridas para avaliar a variabilidade da precipitação pluvial [10, 11], em que inúmeros índices descritos na literatura auxiliam no entendimento da climatologia local [12]. A análise de tendências temporais permite detectar mudanças que algumas variáveis sofrem ao longo do tempo, de origem antrópica ou não [11,13]. O método de Mann-Kendall é utilizado satisfatoriamente para estudar análises temporais das mais diversas variáveis de estudo, sendo um método robusto, sequencial e não paramétrico [13]. Assim, pode ser considerado um método padrão para tais aplicações.

Logo, métodos baseados em procedimentos de fácil processamento e que forneçam informações satisfatórias, a exemplo do proposto neste trabalho, podem contribuir ao planejamento e tomada de decisões por parte de produtores, instituições, e da população. Face ao exposto, objetivou-se definir um procedimento metodológico para análise da variabilidade e anomalia da chuva e do extrato do balanço hídrico climatológico sequencial (BHCS), e suas tendências de mudanças ao longo do tempo, comparando os resultados com o teste padrão (MannKendall). Utilizou-se como base o estudo de caso para o município de Carnaíba, sertão Semiárido do estado de Pernambuco. 


\section{MATERIAL E MÉTODOS}

Utilizou-se uma série histórica de dados de precipitação pluviométrica do município de Carnaíba, Semiárido do estado de Pernambuco (07048'19"S; 3707'38"W e 485m). O clima da região é Semiárido quente, do tipo BSwh' [14]. As atividades desenvolvidas são basicamente a agricultura de sequeiro e, pecuária (bovinos, caprinos e ovinos), além de atividade econômica comercial de pouca expressão $[11,15]$.

Foram utilizados dados climáticos mensais e anuais de chuva, oriundos do posto pluviométrico localizado no município, código de identificação 184, pertencente a Agência Pernambucana de Águas e Clima (APAC), para um período de 40 anos (1965 a 2006), sendo esta, a série mais continua que foi possível obter (exceção dos anos de 1992 e 1993, que possuíam falhas de dados). Estes dados foram exportados para planilhas eletrônicas Microsoft Office Excel e organizadas as séries mensais e anuais. Foi sugerida neste trabalho, a criação de critérios para detectar possíveis mudanças no regime de chuvas em termos de variabilidade e anomalia climática.

Os dados foram submetidos à estatística descritiva e uma metodologia foi proposta para detectar variabilidades e anomalias climáticas pelos desvios da precipitação pluviométrica. Foram obtidas a média $(\mathrm{X})$ e desvio padrão $(\sigma)$ de cada conjunto de dados, procedendo-se com $\mathrm{o}$ enquadramento dos valores de chuva em cinco classes distintas: "Anos Normais", "Variabilidade Climática Superior", "Variabilidade Climática Inferior", "Anomalia Climática Superior" e "Anomalia Climática Inferior". Desta forma, o critério utilizado foi o seguinte:

Anos Normais - Anos com valores compreendidos dentro do limite $(X \pm 1 / 2 \sigma)$;

Variabilidade Climática - Anos com valores compreendidos nos limites $(X \pm 1 / 2 \sigma) \pm(1 / 2 \sigma)$;

Anomalia Climática - Anos com valores compreendidos acima ou abaixo do limite $(\mathrm{X} \pm \sigma)$.

De posse destes critérios, foi feita uma análise de frequência, contabilizando-se a quantidade e percentual de anos em que foi observada sua ocorrência para cada classe estabelecida, por meio do programa Microsoft Office Excel.

O Balanço Hídrico Climatológico Sequencial (BHCS) foi determinado pelo método proposto por Thornthwaite 1948 [16], com auxílio de planilha eletrônica BHseq.xls elaborada por Rolim et al. (1998) [17], utilizando os dados de coordenadas locais, precipitação, temperatura média do ar e da capacidade de água disponível, que foi igual a $100 \mathrm{~mm}$, valor comumente utilizado para fins de caracterização climática de regiões com vegetação semidecidual [17]. Assim, determinaramse os valores de evapotranspiração potencial e real, baseando-se em dados de temperatura do ar e do fotoperíodo, e da variação do armazenamento de água no solo. Assim, o modelo de BHCS fornece estimativas dos períodos de excesso (EXC), deficiência (DEF), retirada e reposição de água no solo [16]. Devido à ausência de dados de temperatura média do ar para a localidade em estudo, fez-se necessário utilizar de uma estimativa desta variável, a qual foi realizada utilizando o programa Estima-T [13]. Este programa foi desenvolvido pela Universidade Federal de Campina Grande (UFCG), o qual é empregado no Nordeste do Brasil para estimação da temperatura, e determina para cada região os coeficientes da função quadrática para as temperaturas médias, máximas e mínimas mensais em função das coordenadas locais (latitude, longitude e altitude), e da anomalia da Temperatura da Superfície do Mar (TSM) dos oceanos Atlântico e Pacífico tropicais [18]. No entanto, devido o método subestimar a evapotranspiração potencial para condições de aridez, fez-se o cálculo da temperatura efetiva local, utilizando as amplitudes da temperatura do ar (máxima e mínima), conforme Equação 1 [16]:

Temperatura $_{\text {efetiva }}=0,36\left(3 \mathrm{~T}_{\text {máx }}-\mathrm{T}_{\text {mín }}\right)$

Para analisar a distribuição intra e interanual da chuva e do extrato do BHCS (Excesso hídrico, Déficit hídrico, Retirada de água do solo e Reposição de água do solo) e verificar possíveis alterações no seu comportamento, procedeu-se com verificações nas tendências lineares dos dados. Utilizou-se o programa SigmaPlot ${ }^{\circledR} 10$ (Systat Software Inc.) para confeccionar os gráficos e realizar as curvas de tendência. Estas foram expressas por modelos de regressões lineares do tipo $y=a+b x$, sendo o $\mathrm{x}$ os anos, e y a variável analisada (precipitação, excesso hídrico, reposição de água, déficit hídrico e retirada de água), $a$ representa o valor da reta ajustada para o tempo $(t=0)$ e $b$ representa o coeficiente angular. As estatísticas das significâncias das equações 
e dos seus respectivos coeficientes, foram avaliadas com base no teste F e t de Student, nesta ordem, admitindo-se como válidos desde que a $\mathrm{p}<0,10$ e $\mathrm{p}<0,05$.

O teste de Mann-Kendall foi aplicado aos dados em nível de comparação, para averiguar os resultados obtidos pelo método sugerido neste estudo. Informações descritivas sobre o método podem ser obtidas em Salviano et al. (2016) [13]. Assim, todos os procedimentos estatísticos do teste de Mann-Kendall foram realizados por meio do programa Statistical Software and Data Analysis in Excel, XLSTAT, versão 2014 (Addinsoft, Paris, França, www.xlstat.com).

\section{RESULTADOS E DISCUSSÃO}

Os totais anuais e a tendência climática dos dados de precipitação pluviométrica para o município de Carnaíba, PE, podem ser visualizados na Figura 1.

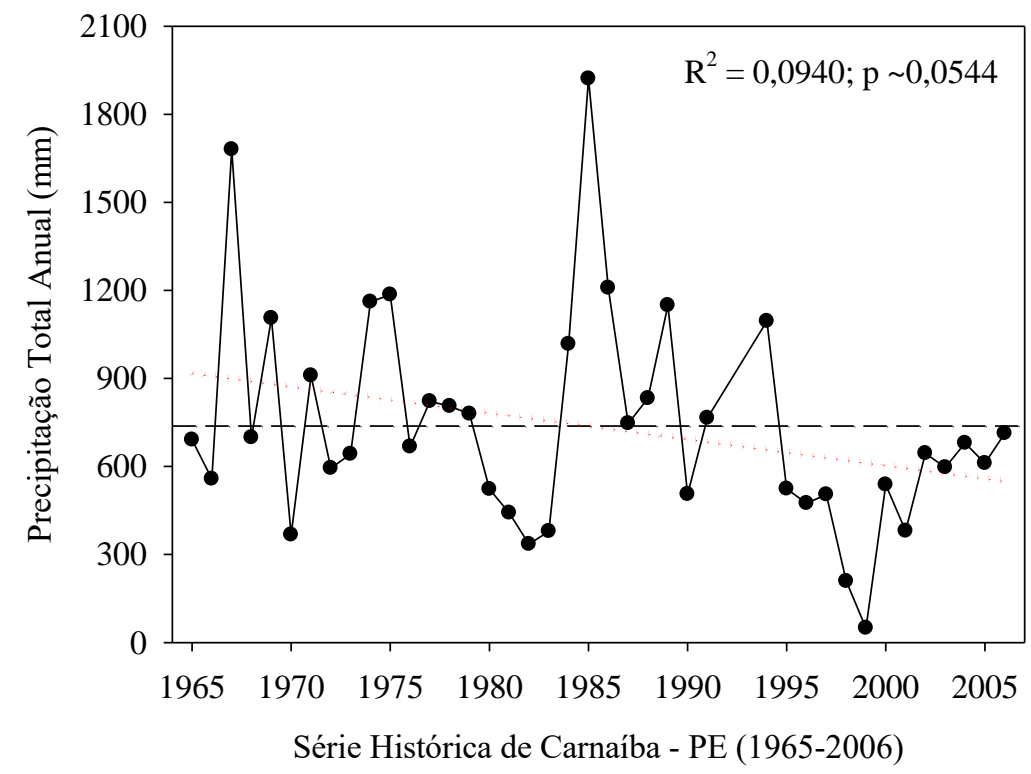

Figura 1 - Regime pluviométrico anual do município de Carnaíba-PE, no período de 1965 a 2006 (40 anos de dados observados). (---) Média anual da série histórica. (…) Linha de tendência linear.

Constatou-se que a média anual de chuva para o município é de 737,6 mm, sendo que ao longo da série analisada (1965-2006) observa-se que o ano de 1985 foi demasiadamente chuvoso, sendo aquele com maior regime pluviométrico observado $(1921,5 \mathrm{~mm})$ e a menor precipitação ocorreu em 1999 (49,6 mm). Observa-se também que a partir de meados da década de 90 até 2006, a chuva anual manteve-se abaixo da média anual (Figura 1). A precipitação pluviométrica anual observada para Carnaíba exibiu uma tendência negativa significativa $(p<0,1)$, retratando que a precipitação total anual está diminuindo. O teste de Mann-Kendall também indicou tendência significativa e negativa da precipitação anual $(\mathrm{p}<0,1 ;-7,42)$.

O comportamento da chuva observado no ano de 1985 (Figura 1) foi evidenciado por Marengo e Valverde (2007) [14] que analisando anomalias de chuva sazonal, durante a estação chuvosa nos meses de fevereiro a maio para a região Nordeste nos anos de 1901 a 1998, usando dados da Climate Research Unit (CRU), verificaram que a partir da década de 1970 a quantidade de chuvas nesta região foi reduzida, quando comparada com anos anteriores, e que o ano de 1985 foi bastante úmido. A tendência observada na Figura 1 permitiu inferir que numa perspectiva de ocorrência de períodos menos chuvosos, onde totais anuais provavelmente abaixo da média sejam mais eminentes, e considerando que a região em análise já apresenta baixos índices pluviométricos, tal informação contribui ao incentivo de mudanças de hábitos de manejo e conservação de água, numa busca por otimizações de técnicas com fins na preservação do domínio de Caatinga, assegurando a sustentabilidade do ecossistema como um todo. 
Silva et al. (2016) [11] citam que avaliações da variabilidade climática baseados em teste de Mann-Kendall, encontraram tendências estatisticamente decrescentes para o Nordeste do Brasil em muitos localidades, tanto em regiões semiáridas como no litoral.

Na Tabela 1, é apresentada a estatística descritiva, assim como o número de anos enquadrados nas classes e sua respectiva porcentagem, para os totais anuais e mensais da precipitação pluviométrica do município de Carnaíba, Pernambuco.

Tabela 1 - Estatística descritiva, número de anos e porcentagem de anos enquadrados nas classes:

"Anos Normais", "Variabilidade Climática Superior", "Variabilidade Climática Inferior”,

"Anomalia Climática Superior" e "Anomalia Climática Inferior”, para valores anuais e mensais da precipitação pluviométrica do município de Carnaíba - PE, no período de 1965 a 2006.

\begin{tabular}{|c|c|c|c|c|c|c|c|c|c|c|c|c|c|}
\hline \multirow{4}{*}{$\begin{array}{l}\mathrm{X}(\mathrm{mm}) \\
\sigma(\mathrm{mm})\end{array}$} & \multicolumn{13}{|c|}{ Períodos analisados } \\
\hline & Anual & Jan & Fev & Mar & Abr & Mai & Jun & Jul & Ago & Set & Out & Nov & Dez \\
\hline & 738 & 81 & 109 & 183 & 145 & 75 & 50 & 29 & 10 & 4,0 & 6,0 & 16 & 31 \\
\hline & 368 & 90 & 94 & 120 & 127 & 63 & 58 & 46 & 18 & 12 & 13 & 25 & 37 \\
\hline \multicolumn{14}{|c|}{ Numero de anos compreendidos nas classes } \\
\hline ACI & 4 & 7 & 6 & 6 & 4 & 6 & 9 & 13 & 22 & 30 & 27 & 20 & 11 \\
\hline VCI & 9 & 7 & 8 & 10 & 12 & 7 & 5 & 4 & 0 & 0 & 0 & 2 & 3 \\
\hline Normal & 18 & 19 & 17 & 14 & 13 & 17 & 19 & 17 & 8 & 5 & 8 & 7 & 17 \\
\hline VCS & 3 & 1 & 4 & 3 & 4 & 5 & 2 & 1 & 6 & 1 & 0 & 5 & 5 \\
\hline ACS & 6 & 6 & 5 & 7 & 7 & 5 & 5 & 5 & 4 & 4 & 5 & 6 & 4 \\
\hline \multicolumn{14}{|c|}{ Porcentagem de ocorrência (\%) } \\
\hline ACI & 10 & 18 & 15 & 15 & 10 & 15 & 23 & 33 & 55 & 75 & 68 & 50 & 28 \\
\hline VCI & 23 & 18 & 20 & 25 & 30 & 18 & 13 & 10 & 0 & 0 & 0 & 5 & 8 \\
\hline Normal & 45 & 48 & 43 & 35 & 33 & 43 & 48 & 43 & 20 & 13 & 20 & 18 & 43 \\
\hline VCS & 8 & 3 & 10 & 8 & 10 & 13 & 5 & 3 & 15 & 3 & 0 & 13 & 13 \\
\hline ACS & 15 & 15 & 13 & 18 & 18 & 13 & 13 & 13 & 10 & 10 & 13 & 15 & 10 \\
\hline
\end{tabular}

A distribuição de frequência dos intervalos de classes de precipitação (Tabela 1), mostrou que para os valores anuais, há maior frequência de anos enquadrados na classe "Anos Normais", com uma porcentagem de ocorrência igual a $45 \%$, equivalente a 18 anos (registros de chuva entre $553,7 \mathrm{~mm}$ e $921,6 \mathrm{~mm}$ ), seguidos de variabilidade climática inferior (VCI) igual a $23 \%$ (valores de chuva compreendidos no intervalo de $369,7 \mathrm{~mm}$ e 553,7 mm) e Anomalia Climática Superior (ACS) (valores acima de $1105,5 \mathrm{~mm}$ ) igual a $15 \%$ (Tabela 1 ).

Em relação à distribuição de frequência dos intervalos de classes de precipitação, entre os meses de dezembro a julho (Tabela 1), existe maior ocorrência de "Anos normais", sendo que naqueles predominantemente mais chuvosos para o município (março e abril) foi observada as maiores frequências de eventos enquadrados na classe ACS (Anomalia Climática Superior), equivalentes a $18 \%$ dos anos analisados, para ambos os meses. Já nos meses de agosto, setembro e outubro, o número de Anomalias Climáticas Inferiores (ausência de chuva) foi maior que 50\%, e no mês de novembro foi de exatamente $50 \%$. O mês de setembro foi aquele com maior frequência de anos anômalos inferiores (ACI), onde em 75\% dos anos observados (equivalente a 30 anos) foram registradas ausência de chuva.

Isso mostra que ao longo da série estudada, nos meses de setembro a dezembro, os eventos de variabilidade e anomalia climática da chuva, abaixo da normal climatológica, foram eventos mais frequentes, e que nos meses mais chuvosos para a região (janeiro a abril) houve maior frequência de anos com ACS.

A análise de distribuição das chuvas em escalas mensais para o município de Carnaíba é observada na Figura 2. 


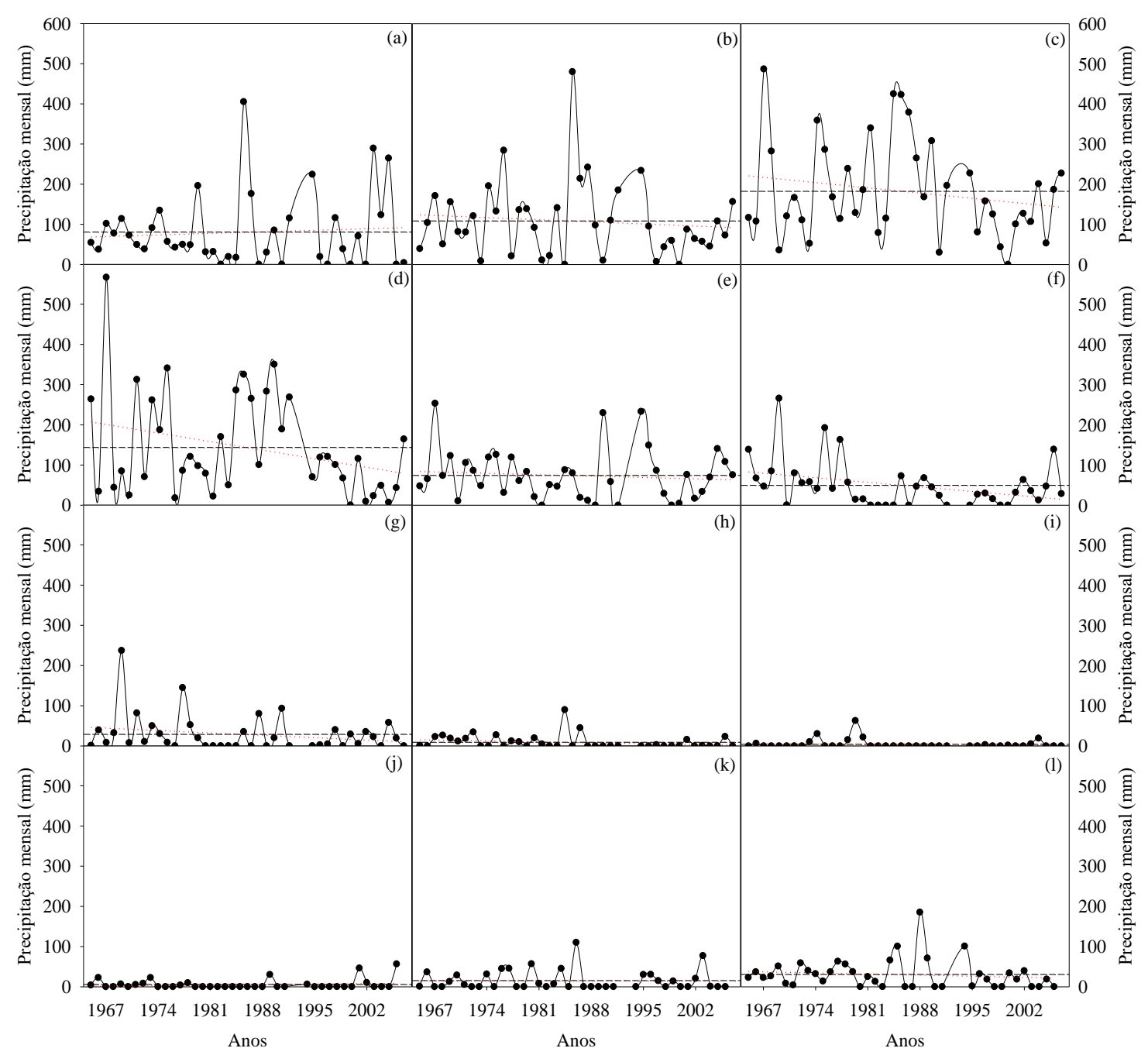

Figura 2 - Regime pluviométrico anual: janeiro (a), fevereiro (b), março (c), abril (d), maio (e), junho $(f)$, julho $(g)$, agosto $(h)$, setembro $(i)$, outubro $(j)$ novembro $(k)$ e dezembro $(l)$ do município de Carnaíba-PE, no período de 1965 a 2006 (40 anos de dados observados). (---) Média mensal da série histórica. (....) Linha de tendência linear.

Os meses de janeiro a abril são aqueles que apresentaram maiores médias mensais de chuva, variando de $80,5 \mathrm{~mm}$ em janeiro e 181,3 mm em março. Nos meses de agosto, setembro e outubro, os totais médios mensais são expressivamente baixos $(9,7 \mathrm{~mm} ; 4,4 \mathrm{~mm}$ e $5,8 \mathrm{~mm}$, respectivamente), ocasionando forte déficit hídrico local. Verificou-se que em todos os meses, já foram registrados ausência de chuva ao longo dos 40 anos avaliados (Figura 2).

A análise mensal da distribuição das chuvas ao longo dos 40 anos (Figura 2) permitiu verificar que existem dois períodos distintos bem marcantes: um primeiro período, onde as chuvas são concentradas entre os meses de janeiro a abril, com chuvas típicas de verão/outono (destaque para os meses de março e abril), e um segundo período com chuvas pouco presentes de maio e dezembro. Entre os meses de agosto a outubro os totais médios mensais reduzem bastante, caracterizando o final do inverno e início da primavera. Desta forma, as estações de inverno/primavera são relativamente secas, mínimo de chuvas em setembro (média de 4,4 mm) e verão/outono mais úmidos, com destaque para o mês de março (média de 183,1 mm).

$\mathrm{O}$ fato de que em todos os meses, já houve registros de ausência de chuvas, indica que, mesmo nos meses mais chuvosos, esta pode não existir, devido a fenômenos de secas que podem ou não, estar relacionados aos efeitos do fenômeno de El Niño, a sazonalidade de sistemas convectivos e atuação de massas de ar responsáveis pela formação das chuvas nesta região [15].

O regime de chuvas observados na região Nordeste, de forma geral, sofre grande influência do deslocamento da Zona de Convergência Intertropical (ZCIT), também conhecida como zona de 
convergência dos ventos alísios [12]. A ZCIT durante a declinação mínima solar pode atingir latitudes de até $8^{\circ} \mathrm{Sul}$, sendo as chuvas do Nordeste mais abundantes nesta estação, além disso, a variabilidade interanual da chuva nesta região também está relacionada com as oscilações dos padrões de Temperatura da Superfície do Mar (TSM) que ocorrem nos oceanos tropicais, o qual contribui para variações na intensidade e posição da ZCIT [9].

Marengo e Valverde (2007) [18] citam que a existência de tendência de longo prazo na precipitação pluviométrica da região Nordeste, caracterizado por um deslocamento da ZCIT e banda de chuvas mais para o Sul da sua posição climatológica, poderiam justificar as tendências positivas de chuva no Nordeste, onde de acordo com revisão realizada por estes autores, devido ao aquecimento sistemático do Atlântico Tropical Sul que é observado predominantemente nos meses de verão, a ZCIT se desloca mais para o Sul e as chuvas no Norte do Nordeste tendem a incrementar.

Em relação a análise na detecção de tendências climáticas no padrão pluviométrico para os valores mensais ao longo da série avaliada, os resultados mostraram que apenas o mês de junho apresentou tendência significativa de redução da precipitação (Figura 2f), indicando que neste mês, os eventos de chuva tendem a ser inferiores à média registrada, e sendo assim, menos chuvoso que o habitual. A aplicação do teste de Mann-Kendall aos dados mensais de chuva identificaram tendências significativas $(\mathrm{p}<0,1)$ e negativas $(-1.06)$ para o mês de junho, enquanto para os demais meses, embora observadas tendências positivas e negativas, estas não foram estatisticamente significativas (dados não mostrados). Confirmando os dados obtidos pelo teste Mann-Kendall, observa-se que praticamente não houve tendências para os meses de janeiro, fevereiro, maio, agosto, setembro, outubro, novembro e dezembro (Figura 2a, 2b, 2e, 2h, 2i, 2j, $2 \mathrm{k}, 2 \mathrm{l}$ ), e que os demais meses apresentaram tendências negativas, porém, estas não são estatisticamente significantes, de modo que, não é seguro afirmar que estas tendências realmente estão ocorrendo. Nota-se que, naqueles meses em que as chuvas são escassas, com valores oscilando entre $0 \mathrm{~mm}$ e $30 \mathrm{~mm}$, são os meses em que não se verificaram tendências (exceção de janeiro, fevereiro e março), justamente porque os índices de precipitação já são os menores possíveis (Precipitação $=0 \mathrm{~mm}$ ).

Souza e Azevedo (2012) [5] verificaram as tendências da precipitação pluviométrica e das temperaturas máximas e mínimas para o município de Recife, Pernambuco, por meio de índices de detecção de mudanças climáticas, utilizando o programa RClimdex. Estes autores constataram que os resultados derivados da chuva não apresentaram tendências significativas de redução, no entanto, todos os índices foram analisados evidenciando a ocorrência de tendências positivas ou negativas, e sua contribuição para o entendimento da variabilidade da precipitação. Tais resultados foram associados às alterações observadas a mudança climática global, e especificamente, às ações antropogênicas oriundas de modificações do ambiente.

Os componentes do BHCS, os quais são representados pelo Excesso e Déficit Hídrico, e pela Retirada e Reposição de Água do Solo, para o município de Carnaíba, apresentaram oscilação de seus valores médios anuais ao longo dos 40 anos analisados (Figura 3). 

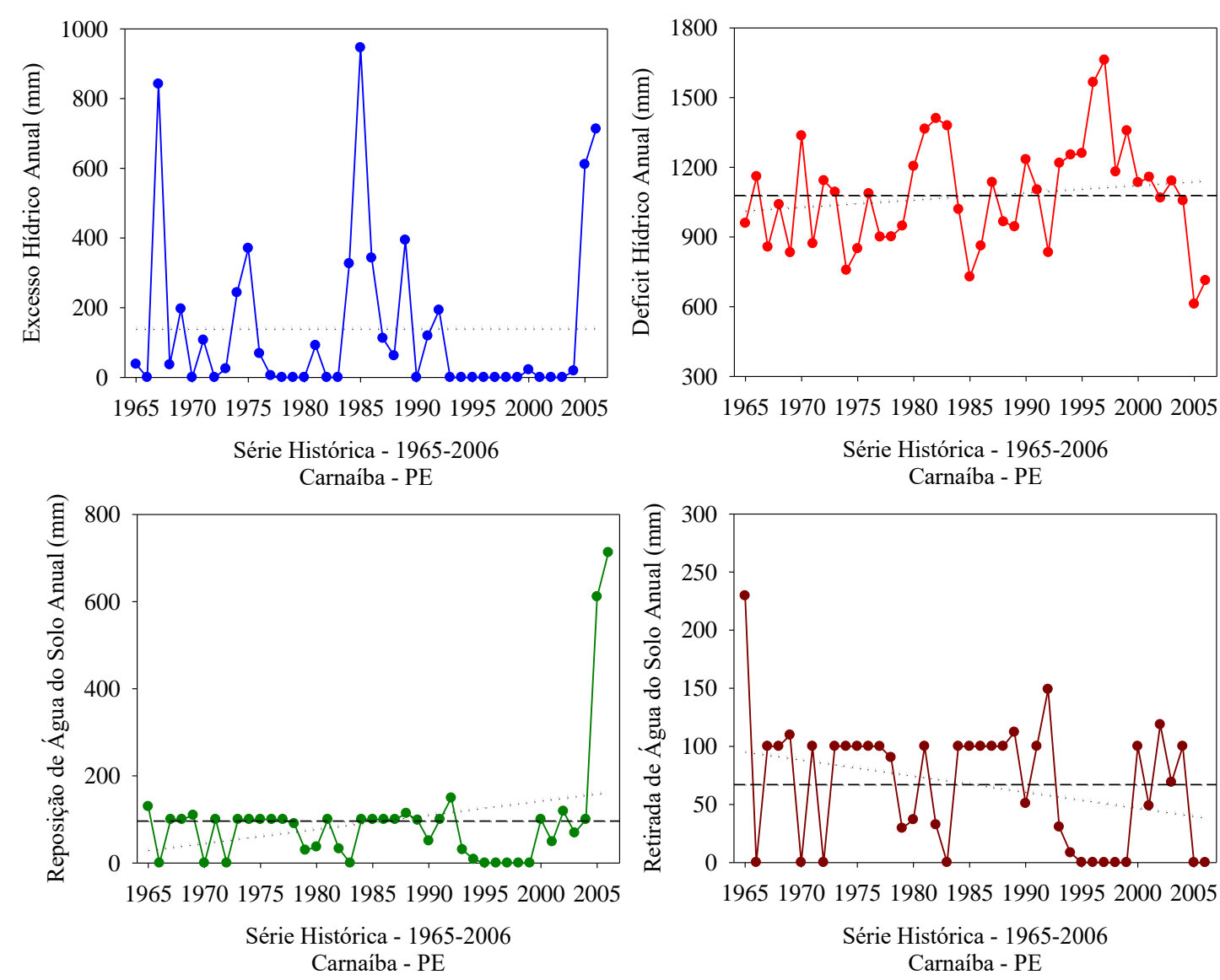

Figura 3 - Componentes do BHCS: Excesso Hídrico (a), Déficit Hídrico (b), Retirada de Água do solo (c) e Reposição de Água do solo (d) do município de Carnaíba-PE, no período de 1965 a 2006 (40 anos de dados observados). (---) Média anual da série histórica. (…) Linha de tendência linear.

Verificou-se que para o Excesso hídrico, não foram verificadas tendências de seus valores (p $>0,10$ ). De modo geral, na maioria dos anos verificou-se ausência de excessos hídricos, onde nos 40 anos analisados, apenas em 11 deles, constataram-se excessos acima da média, com destaque para os anos de 1967, 1985, 2005 e 2006 (Figura 3a). Em relação ao déficit hídrico, este foi superior a $700 \mathrm{~mm}$ em praticamente todos os anos, com exceção do ano de 2005 (611 mm) (Figura $3 b$ ), porém, também não foram verificadas tendências de aumento ou redução deste componente do BHCS (Figura 3). Para o teste não paramétrico de Mann-Kendall, verificaram-se tendências significativas e positivas para o déficit hídrico anual $(6,42)$.

Os resultados obtidos para o BHCS permitiram verificar que, devido à alta demanda atmosférica e os baixos valores anuais de precipitação, a ocorrência de excesso hídrico e de reposição de água no solo são pouco observados em locais situados no Semiárido, conforme visto na Figura 3. Em contrapartida, elevados valores de déficit hídrico são corriqueiros, sendo este, um indicativo do forte grau de estresse que a vegetação local está submetida. A região Semiárida é caracterizada por um balanço hídrico negativo, em que as precipitações são inferiores a $800 \mathrm{~mm}$ e a evaporação média está em torno de $2.000 \mathrm{~mm} \mathrm{ano}^{-1}$, favorecendo assim, o constante déficit hídrico [9, 16]. Silva et al. (2011) [17] em estudos realizados no estado de Pernambuco, informam que, mesmo nos meses de chuvas regulares, o déficit hídrico do estado pode chegar a $65 \%$, advertindo que o uso de técnicas de irrigação e de culturas resistentes ao déficit hídrico são essenciais.

Posteriormente, foi realizada a análise mensal do extrato do BHCS, no entanto, são apresentados apenas os componentes do extrato que apresentaram tendências significativas. A Figura 4 apresenta os totais mensais e a tendência climática do Déficit hídrico. 


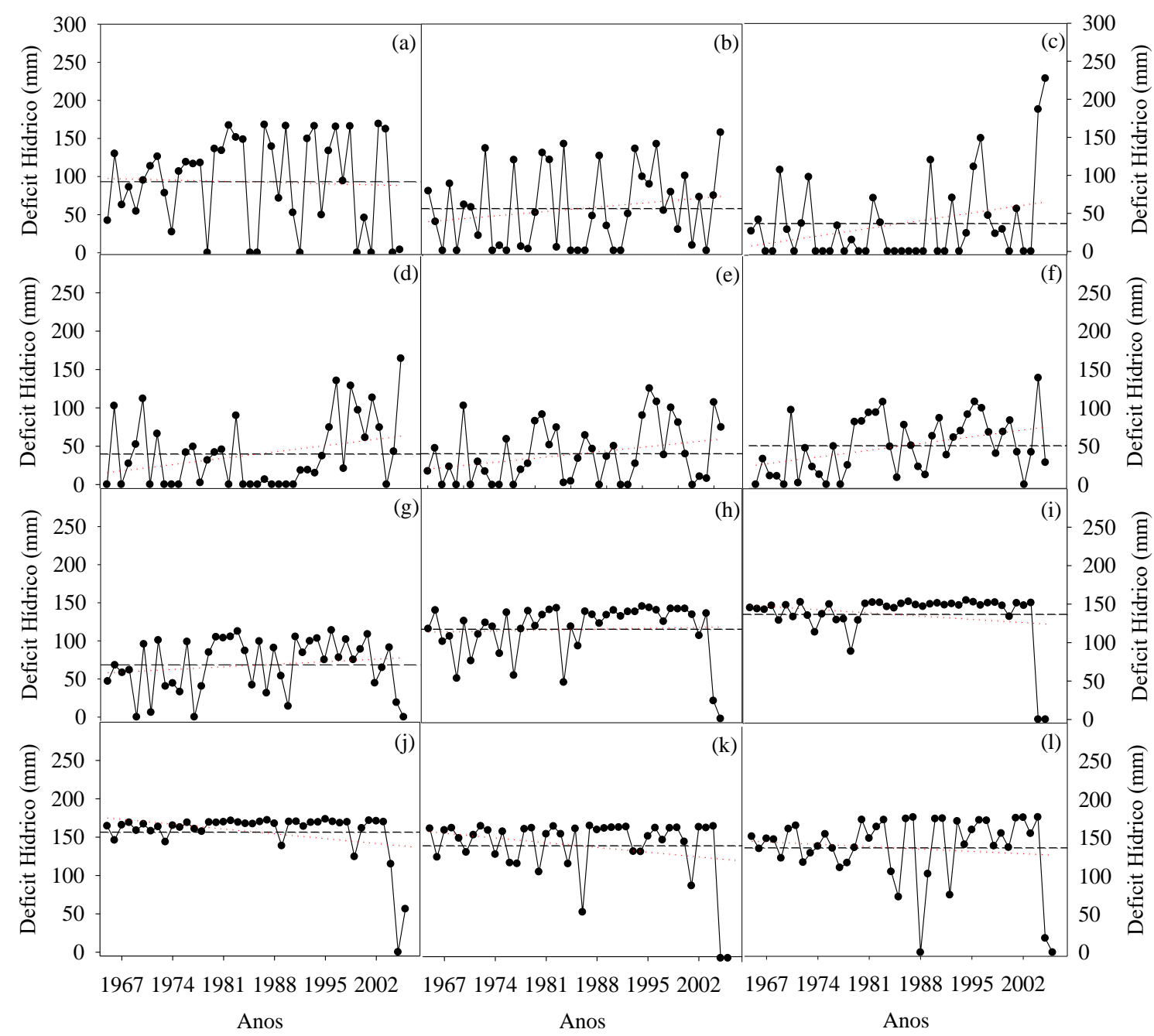

Figura 4 - Déficit Hídrico mensal: janeiro (a), fevereiro (b), março (c), abril (d) maio (e), junho ( $f$ ), julho $(g)$, agosto $(h)$, setembro $(i)$, outubro $(j)$ novembro $(k)$ e dezembro $(l)$ observado para o município de Carnaíba-PE, no período de 1965 a 2006 (40 anos de dados observados). (---) Média anual da série histórica. ("…) Linha de tendência linear.

Verificou-se que houve deficiência de água em todos os meses avaliados e que apenas em alguns anos, este componente, em termos mensais, se aproximou de zero (Figura 4). Os meses de março, abril, maio e junho apresentaram tendências significativas $(\mathrm{p}<0,10)$, indicando que nestes meses a tendência é de que os valores de déficit hídrico aumentem (Figuras 4c, 4d, 4e, 4f). Já os meses de outubro e novembro apresentaram tendências de redução do déficit hídrico $(p<0,10)$ (Figuras $4 \mathrm{j}, 4 \mathrm{k}$ ). Entre os meses de agosto a janeiro, o déficit hídrico médio mensal ficou na faixa entre 100 e $150 \mathrm{~mm}$ (Figura 4h, 4i, 4j, 4k, 4l, 4a), enquanto que nos meses de fevereiro a julho este foi próximo a $50 \mathrm{~mm}$ (Figura 4b, 4c, 4d, 4e, 4f, 4g). Para a análise de Mann-Kendall, o Déficit Hídrico mensal apresentou apenas tendências significativas e positivas durante os meses de junho $(1,16)$, julho $(0,83)$, agosto $(0,75)$, setembro $(0,20)$ e outubro $(0,13)$.

$\mathrm{O}$ armazenamento de água no solo pode sofrer varias modificações ao longo do ano, sendo representado pelos componentes Retirada e Reposição de água no solo, obtidos do BHCS. Em relação aos valores de Retirada de água do solo, houve tendência significativa para alguns meses avaliados, sendo que entre os meses de abril a agosto, são observadas as maiores retiradas de água (Figura 5). 


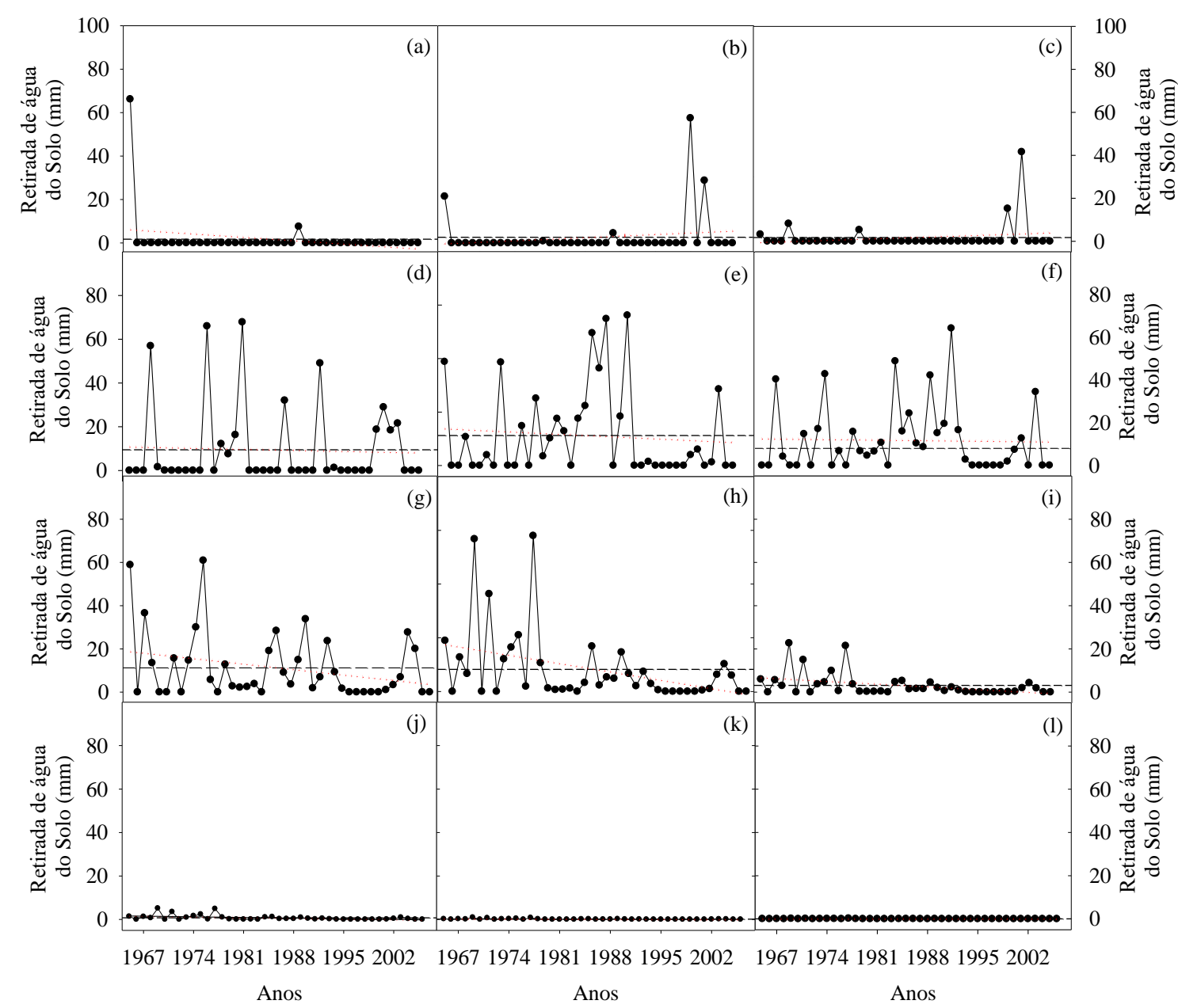

Figura 5 - Retirada de Água do Solo mensal: janeiro (a), fevereiro (b), março (c), abril (d) maio (e), junho $(f)$, julho $(g)$, agosto $(h)$, setembro $(i)$, outubro $(j)$ novembro $(k)$ e dezembro $(l)$ observado para o município de Carnaíba-PE, no período de 1965 a 2006 (40 anos de dados observados). (---) Média anual da série histórica. (…) Linha de tendência linear.

A Retirada de água do solo tendeu a aumentar ao longo dos anos, sendo os meses de abril a julho aqueles com maiores retiradas de água do solo (Figura $5 \mathrm{~d}, 5 \mathrm{e}, 5 \mathrm{f}, 5 \mathrm{~g}$ ). Houve tendência significativa negativa $(\mathrm{p}<0,10)$ para os meses de janeiro, julho, agosto e setembro, permitindo afirmar que nestes meses as retiradas de água do solo tendem a serem menores (Figuras 5a, 5g, 5h, 5i). Similarmente, o teste padrão (Mann-Kendall), indicou apenas tendências negativas para esta variável (Retirada), com os meses de agosto a janeiro apresentando tendências significativas. Tais informações confirmam os resultados obtidos neste estudo, uma vez que, nos meses de outubro a dezembro (que não foram obtidas tendências pelo método proposto) as tendências (teste de Mann-Kendall), embora significativas, foram muito baixas (-0,006 a -0,01).

A retirada de água do sistema solo é feita principalmente pela vegetação, deste que se tenha água disponível. Os meses de abril a julho são aqueles com maiores retiradas de água do solo (Figura 5), uma vez que são os meses subsequentes ao período chuvoso da região (Figura 2), sendo que neste período, a água está mais disponível para que as plantas possam utiliza-la em seus processos internos.

Tais considerações reforçam a hipótese de que em algumas áreas do Semiárido, a agricultura de sequeiro é de risco, sendo necessário o uso de irrigação, e que as altas temperaturas podem influenciar negativamente a produtividade de culturas anuais irrigadas e perenes [16, 18]. 


\section{CONCLUSÃO}

O procedimento metodológico proposto para análise de variabilidade e anomalia da chuva apresentou bons resultados quando comparado às tendências obtidas pelo teste de Mann-Kendall. Para o município de Carnaíba, a classe de eventos de chuva dita como "Anos Normais" foi mais frequente, seguida de eventos de variabilidade climática inferior e anomalia climática superior. Dentre os componentes do extrato do BHCS, o déficit hídrico é aquele de maior ocorrência, indicando que a disponibilidade hídrica local é bastante reduzida.

\section{AGRADECIMENTOS}

A Agência Pernambucana de Água e Clima - APAC, pela disponibilidade dos dados. Ao grupo GAS - Grupo de Agrometeorologia no Semiárido.

\section{REFERÊNCIAS BIBLIOGRÁFICAS}

1. Rai A, Singh AK, Ghosal N, Singh N. Understanding the effectiveness of litter from tropical dry forests for the restoration of degraded lands. Ecol Eng [Internet]. 2016;93:76-81. Available from: http://dx.doi.org/10.1016/j.ecoleng.2016.05.014

2. Correia GG de S, Martins SV, Miranda Neto A, Silva K de A, Correia GG de S, Martins SV, et al. Estoque de serapilheira em floresta em restauração e em floresta atlântica de tabuleiro no sudeste brasileiro. Rev Árvore [Internet]. 2016 Feb [cited 2017 Jul 25];40(1):13-20. Available from: http://www.scielo.br/scielo.php?script=sci_arttext\&pid=S0100-67622016000100013\&lng=pt\&tlng=pt

3. Coelho VHR, Montenegro SMGL, Almeida C das N, Lima ERV de, Ribeiro Neto A, Moura GSS de. Dinâmica do uso e ocupação do solo em uma bacia hidrográfica do semiárido brasileiro. Rev Bras Eng Agrícola e Ambient [Internet]. 2014 Jan [cited 2017 Jul 25];18(1):64-72. Available from: http://www.scielo.br/scielo.php?script=sci_arttext\&pid=S1415-43662014000100009\&lng=pt\&tlng=pt

4. Santos CAC dos, Brito JIB de. Análise dos índices de extremos para o semi-árido do Brasil e suas relações com TSM e IVDN. Rev Bras Meteorol [Internet]. 2007 Dec [cited 2017 Jul 25];22(3):303-12. Available from: http://www.scielo.br/scielo.php?script=sci_arttext\&pid=S0102$77862007000300003 \& \operatorname{lng}=\mathrm{pt} \& \ln \mathrm{g}=\mathrm{pt}$

5. Souza WM de, Azevedo PV de A. Índices de Deteç̧ão de Mudanças Climáticas Derivados da Precipitação Pluviométrica e das Temperaturas em Recife-PE. Rev Bras Geogr Física. 2011;6:127591.

6. Oliveira FT de, Souto JS, Silva RP da, Filho FC de A, Júnior EBP. Palma Forrageira: Adaptação e importância para os ecossistemas áridos e semiáridos. Rev Verde. 2010;5(4):27-37.

7. Silva JC, Heldwein AB, Martins FB, Trentin G, Grimm EL. Análise de distribuição de chuva para Santa Maria, RS. Rev Bras Eng Agrícola e Ambient Eng Agrícola e Ambient. 2007;11(55):67-72.

8. Alves EDL. Frequência e probabilidade de chuvas no município de Iporá-GO. Caminhos Geogr. 2011;12(37):65-72.

9. Moura MSB de, Galvincio JD, Brito LT de L, Souza LSB de, Sá IIS, Silva TGF da. Clima e água de chuva no semi-árido. In: Potencialidades da água de chuva no Semi-Árido brasileiro [Internet]. 2007. p. 37-59. Available from: http://www.alice.cnptia.embrapa.br/handle/doc/159649

10. Silva V de PR da, Pereira ERR, Almeida RSR. Estudo da variabilidade anual e intra-anual da precipitação na região Nordeste do Brasil. Rev Bras Meteorol [Internet]. 2012 Jul [cited $2017 \mathrm{Jul}$ 25];27(2):163-72. Available from: http://www.scielo.br/scielo.php?script=sci_arttext\&pid=S0102$77862012000200005 \& \operatorname{lng}=\mathrm{pt} \& \ln \mathrm{g}=\mathrm{pt}$

11. Silva VPR da, Pereira ERR, Azevedo PV de, Sousa F de AS de, Sousa IF de. Análise da pluviometria e dias chuvosos na região Nordeste do Brasil. Rev Bras Eng Agrícola e Ambient [Internet]. 2011 [cited 2017 Jul 25];15(2):131-8. Available from: http://www.scielo.br/scielo.php?script=sci_arttext\& $\mathrm{pid}=\mathrm{S} 1415-43662011000200004 \& \operatorname{lng}=\mathrm{en} \& \mathrm{nrm}=\mathrm{iso} \& \mathrm{t} \operatorname{lng}=\mathrm{pt}$

12. Costa JA, Djane Fonseca Da Silva. Revista Brasileira de Geografia Física. Rev Bras Geogr Física. 2017;10(4):1002-13.

13. Salviano MF, Groppo JD, Pellegrino GQ. Análise de tendências em dados de precipitação e temperatura no Brasil. Rev Bras Meteorol. 2016;31(1):64-73.

14. Alvares CA, Stape JL, Sentelhas PC, Gonçalves JLM, Sparovek G. Köppen's climate classification map for Brazil. Meteorol Zeitschrift. 2013;22:711-28.

15. Martins MA, Tomasella J, Rodriguez DA, Alvalá RCS, Giarolla A, Garofolo LL, et al. Improving 
drought management in the Brazilian semiarid through crop forecasting. Agric Syst [Internet]. 2018;160(November 2016):21-30. Available from: https://doi.org/10.1016/j.agsy.2017.11.002

16. Vianello RL, Alves AR. Meteorologia básica e aplicações. 2nd ed. Viçosa, MG: UFV; 2012.460 p.

17. Rolim GS, Sentelhas PC, Barbieri V. Planilhas do ambiente EXCELTM para os cálculos de balanços hídricos: normal, sequencial, de cultura e de produtividade real e potencial. Rev Bras Agrometeorol. 1998;6(133-137).

18. Cavalcanti EP, Silva V de PR, Sousa F de AS de. Programa computacional para a estimativa da temperatura do ar para a região Nordeste do Brasil. Rev Bras Eng Agrícola e Ambient [Internet]. 2006 Mar [cited 2017 Jul 25];10(1):140-7. Available from: http://www.scielo.br/scielo.php?script=sci_ arttext\&pid=S1415-43662006000100021lng=pt\&tlng=pt

19. Marengo JA, Valverde MC. Caracterização do clima no Século XX e Cenário de Mudanças de clima para o Brasil no Século XXI usando os modelos do IPCC-AR4. Rev Multiciência. 2007;(8):5-28.

20. Mendonça, F.; Danni-Oliveira IM. Climatologia: Noções básicas e climas do Brasil. São Paulo: Oficina de textos; 2007. 206 p.

21. da Silva AO, Moura GB de A, Klar AE. Classificação climática de thornthwaite e sua aplicabilidade agroclimatológica nos diferentes regimes de precipitação em pernambuco. Irriga. 2014;19(1):46-60.

22. Silva AOA da, Moura GB de, França e Silva ÊF de, Lopes PMO, Silva APN. Análise espaço-temporal da evapotranspiração de referência sob diferentes regimes de precipitações em Pernambuco. Rev Caatinga. 2011;24(2):135-42.

23. Medeiros SRR, Moura GBA, Giongo PR, Silva APN. Potencial agroclimático para a Alpinia purpurata, no Estado de Pernambuco. Rev Bras Eng Agrícola e Ambient [Internet]. 2009 Apr [cited 2017 Jul 25];13(2):165-9. Available from: http://www.scielo.br/scielo.php?script=sci_arttext\&pid=S1415$43662009000200009 \& \operatorname{lng}=\mathrm{pt} \& \ln \mathrm{g}=\mathrm{pt}$ 